\title{
Personality of Students of Economics, Medicine, and Verbal Communication: Preliminary Results
}

\author{
Jörg Richter ${ }^{1}$, Rosina Neumann ${ }^{2}$ \\ ${ }^{1}$ Centre for Child and Adolescent Mental Health, Oslo, Norway; \\ ${ }^{2}$ Faculty of Philosophy, University of Rostock, Rostock, Germany. \\ Email: jrichterj@web.de \\ Received December 18 $8^{\text {th }}, 2010$; revised March $18^{\text {th }}, 2011$; accepted April $20^{\text {th }}, 2011$.
}

\begin{abstract}
Differences on personality between students of economics, medicine and verbal communication should be explored by means of the Temperament and Character Inventory. Students of economics are mainly characterized by lower harm avoidance and lower reward dependence and higher self directedness than medical students and students of verbal communication. Students of all groups seem to overestimate their self-directedness with economical students showing the most pronounced tendency of overrating, whereas medical students tend to overrate their cooperativeness more than the students from the other groups. The obvious disturbed self-evaluation corresponds to the students' professional orientation. The students can be characterized by specific and varying types and impact of social desirability depending on their professional career.
\end{abstract}

Keywords: Personality, Temperament, Character, University Students

\section{Introduction}

The personality of university students has been the subject of various investigations, which however focused mainly on relationships between personality characteristics and academic performance. E.g., studies in students of economics showed that those who were more introvert according to the broad MyersBriggs categories and who found their source of energy in the inner life of ideas or concepts, performed better than extroverts in principles of economics. This tendency seemed to persist throughout the university training (Ziegert, 2000; Borg \& Stranahan, 2002a, 2002b). Furthermore, students with SJ (sensing and judging) temperaments, i.e. who trust data and information perceived thru the five senses, who focus on details and specifics, work sequentially and prefer experience-guided learning, and who have a practical and present orientation combined with goal orientation and structured goal planning, performed significantly better than those of a SP (sensing and perceiving) temperament, i.e. who also trust data and information from the five senses but combined with rather spontaneous and flexible preferences and a tendency to avoid quick decisions.

By using the NEO-PI-R questionnaire which is based on the Five-Factor Model of personality (Costa \& McCrae, 1992), Lievens, Coetsier, de Fruyr, \& de Maeseneer (2002) showed that medical students were characterized as highly extrovert without significant differences compared to students of law, economics, psychology, pedagogical sciences and political and social sciences. Additionally, medical students obtained the highest scores on agreeableness and average scores for consciousness, openness to experience and neuroticism. The two dimensions on which, among others, medical students and students of economics differed from students of mainly applied sciences (engineering) refer to interpersonal relationships such as extraversion (sociable and extrovert vs. shy and introvert) indicating the frequency of relationships and agreeableness (warm and friendly vs. cold and aloof) indicating the quality of relationships.

More recently, Cloninger (Cloninger, Przybeck, Svrakic, \& Wetzel, 1994) proposed a new psychobiological model of personality. An assumed distinction between temperament and character seems to be related to differences in major brain systems for the adaptation to the experiences on various levels which can be described as the contrast between percept versus concept, emotion versus volition, instinct versus will, and habit versus cognition. The temperament dimensions are defined to be genetically homogenous and independently inherited. These inherited neurophysiological mechanisms influence tendencies to activate (novelty seeking-NS), maintain (reward dependence-RD), or inhibit (harm avoidance-HA) behaviour and determine the perception of the environment and society. According to this theory, HA reflects a heritable bias in the inhibition or cessation of behaviours. Subjects high in HA are pessimistic, worrying, and fatigable, shy with strangers, and become tense in unfamiliar situations. NS is viewed as a tendency towards exhilaration in response to novel stimuli or cues. Subjects scoring high in NS are described as showing an increased frequency of explanatory behaviour, impulsive decision-making, a quick loss of temper and active avoidance of frustration. RD reflects a tendency to maintain or pursue ongoing behaviours. People with high scores on RD are sentimental, socially attached and dependent on the approval of others. Persistence (PS), the fourth temperament dimension, reflects the perseverance in behaviour despite frustration and fatigue.

Character is defined as individual differences in self-concepts, which vary in the extent to which a person identifies him/herself as an autonomous individual (self-directedness$\mathrm{SD}$ ), as an integrated part of the humanity (cooperativeness$\mathrm{CO}$ ), and as an integral part of the whole universe (self-transcendence-ST). It represents the second domain of personality, which is predominantly determined by socialisation processes 
during the life span. Changes in cognition and the self-concept during the development of personality are supposed to be related to personal, social, moral, and spiritual maturation. An individual, who is low in $\mathrm{SD}$, could be described as irresponsible, aimless, undisciplined in behaviour and of poor impulse-control in general. $\mathrm{CO}$ is related to the extent to which a person identifies himself or herself as an integral part of the society as a whole. Uncooperative individuals are characterised as hostile, aggressive, hateful, and as revengeful opportunists. ST reflects the tendency of identification with unity of all things and is associated with deficits in transpersonal identification or conscience. Individuals low in ST show conventional and materialistically oriented behaviour with little or no concern for absolute ideas, such as goodness and universal harmony. The theory assumes that personality is determined by an interaction between social, environmental, and genetic influences during the whole life span.

Based on this theory, Vaidya and colleagues (2005) investigated a large sample of medical students by means of the related questionnaire, the Temperament and Character Inventory (Cloninger et al., 1994), with focus on differences in personality characteristics between students of various medical specialities. The authors described mainly differences between the students groups concerning temperament dimensions, i.e., future surgeons were lower in HA and RD than others, students choosing primary care specialities, emergency medicine, obstetrics and gynaecology were high on RD with paediatricians scoring highest.

This topic of personality differences between medical students who decided for various medical specialties has of been investigated primarily suggesting that those who preferred any surgical specialty described themselves as being more resistant to stress and having high self-esteem (Linn \& Zeppa, 1984); as more masculine and lower on depression (Zeldow \& Daugherty, 1991); or as high on impulsive sensation seeking and low on neuroticism-anxiety (Hojat \& Zuckerman, 2008) compared to medical students who preferred other specialties. For example, those who were interested in a hospital-based specialty scored lower on sociability.

Generally, persons who have decided to study at university will assume some kind of managing or leading position after some years of occupation. Investigations revealed differences in personality characteristics between students of various specialities (Buddeberg-Fischer, Klaghofer, Abel, \& Buddeberg, 2003). From an organizational psychological perspective, personality characteristics assessed by measures of the five factor model of personality were found associated with career interests corresponding to types of occupational environment based on Holland's theory of career interest $(1985,1994)$. Strong associations were particularly found between the enterprising (individuals with this interest type generally like persuading or directing others more than working on scientific or complicated

\footnotetext{
${ }^{1}$ Currently, this is a B.A. study at the Philosophical Faculty, University of Rostock, mainly aiming to teach pedagogs in a wide range of applied communication sciences with the focus from rehabilitation centres and schools for disabled children to communication disturbances in intercultural team-work. Students should become prepared to deal with phenomena of verbal communication that deviate from common communication processes. Furthermore, they are trained in understanding and management of disturbed communication in various contexts (http://www.phf.uni-rostock.de/institut/igerman/spr komm/html/studiengang.html).
}

topics) and artistic (individuals with this interest type generally like working with creative ideas and self-expression more than routines and rules) vocational interest type and the openness and extraversion personality traits in meta-analyses (Larson, Rottinghaus \& Borgen, 2002; Barrick, Mount, \& Gupta, 2003).

However, we could not find any longitudinal investigation that followed the personality development from a university student to a more or less successful professional career. Therefore, we decided to initiate a 20 years survey of personality in university students of various specialities with waves of two years interval. The following research questions will be investigated: (A) Are there differences between medical students, of verbal communication and communication disturbances and students of economics concerning personality characteristics? (B) Can the personality characteristics of these student groups as assessed by the Myers-Briggs temperament types and/or by the NEO-PI-R be confirmed by the TCI (i.e., a cross-validation of former results and of the construct validation of the TCI)? (C) Are the responses of students from various specialities differently determined by tendencies of self-presentation (i.e., of varying impact of social desirability)? (D) Are there differences in the development of personality characteristics throughout the period of university training and subsequent years depending on the speciality, place of work, position, and/or major changes in private life?

Preliminary results of the $1^{\text {st }}$ wave of this survey are presented below. The study design does not allow addressing the research question $\mathrm{D}$ at this juncture.

\section{Methods}

\section{Sample}

Students of economics $(n=84)$, medicine $(n=65)$, and of verbal communication and communication disturbances $(\mathrm{n}=$ $43)^{1}$ of the University of Rostock, Germany, were willing to participate voluntarily in a 20 -years follow-up study on personality characteristics between January 2004 and June 2005. It represents a convenient sample. The mean age was $22.4 \pm 2.4$ years. There was no significant difference between the three study groups according to age $(\mathrm{F}=0.38 ; \mathrm{p}=0.687)$ or gender $\left(\chi^{2}=0.43\right.$; approx. $\left.p=0.805\right)$. In the instruction, it was clearly stated that this investigation cannot be performed anonymously due to its repeated measures design. We intend investigating the students very two years by the Temperament and Character Inventory and a life event list.

\section{Measurement}

The Temperament and Character Inventory (TCI) (Cloninger et al., 1994) was used to measure temperament and character as major personality domains. It measures the four temperament dimensions based on Cloninger's unified biosocial theory of personality: NS (novelty seeking) and HA (harm avoidance), both composed of four lower-order subscales; RD (reward dependence), composed of three subscales; and, PS (persistence), as a single-scale dimension; as well as the three character dimensions: SD (self-directedness) and CO (cooperativeness), each comprising five lower-order dimensions, and ST (self transcendence) with three subscales. 
The inventory is a self-administered paper-and-pencil test of 240 items of a true/false format. It takes about 20 to 30 minutes to complete. Its psychometric properties have been demonstrated separately for versions of several languages (for the German version Richter, Eisemann, Richter \& Cloninger, 1999) using established personality theories, in different groups of normals and patients, and with respect to neurobiological parameters.

\section{Statistics}

To compare the mean scores between the students' groups, t-tests for independent groups, one-way ANOVAs concerning the personality scores and multiple ANOVAs concerning the personality profile were calculated. In order to evaluate the impact of self-presentation, the so-called performance scores, personality scores derived by multiple regression analysis from validity scores indicating the individual formal response style, were compared with the real response scores by paired-sample t-test (Table 2).

\section{Results}

At the dimensional and sub-scale level, students of economics scored lower on 'NS3 Extravagance vs. Reserve', 'HA1 Anticipatory Worry vs. Optimism', 'HA3 Shyness with Strangers', HA dimension, 'RD1 Extravagance vs. Reserve', RD dimension, whereas they obtained higher scores on 'SD3 resourcefulness vs. inertia', 'SD5 Congruent second nature vs. bad habits' and the SD dimension than medical students followed by the students of verbal communication sciences. Medical students and students of verbal communication did not significantly differ in any of the personality scores (Table 1). Economics students and those of communication were similar on 'CO5 Pure hearted principles vs. self-serving advantage' whereas medical students reached higher scores.

At the multivariate level, we found a main effect for the students' specialty at the level of the sub-scales (Wilks' $\lambda=0.625$; $\mathrm{F}(50 / 322)=1.75 ; \mathrm{p}=0.002 ; \eta .^{2}=0.21$; Power $\left.=1.00\right)$ based on significant effects on NS3, HA1, HA3, HA4, RD1, SD2, $\mathrm{SD} 3, \mathrm{SD} 5$, and CO5). In a MANOVA using the TCI dimensions, main effects for students' specialty (Wilks' $\lambda=0.817$; $\mathrm{F}$ $(14 / 366)=2.77 ; p=0.001 ; \eta .^{2}=0.094 ;$ Power $=0.992$-based on HA, RD and SD) and gender (Wilks' $\lambda=0.920 ; \mathrm{F}(7 / 182)=$ $2.27 ; \mathrm{p}=0.030 ; \eta .^{2}=0.080$; Power $=0.830$ —based on CO) occurred.

The significant differences (paired sample t-tests) between the test scores of the students and the corresponding, evaluated performance scores make us assume that students of all groups seem to overestimate their SD (self-directedness) with economical students showing the most pronounced tendency of overrating, whereas medical students tend to overrate their $\mathrm{CO}$ (cooperativeness) more than the students from the other groups. Additionally, students of economics and medical students overrate their persistence. However, the students of social communication and the medical students seem to a somewhat lesser degree overrate their reward dependence whereas the economical students, on average, highly underrate their HA (harm avoidance). Concerning the number of students who over- or underrate their personality traits, about one third of all students overrate their self-directedness (Table 3) with an overrepresentation of females ( $40 \%$ vs. $25 \%)$ and most pronounced among the medical students ( $42 \%$ vs. 18\%). Furthermore, about one sixth of the medical and one seventh of the economics students overrate their persistence, one tenth of the medical students overrate their cooperative abilities, one tenth of the students of verbal communication overrate their dependency on rewards and one fifth of the students of economics underrate their harm avoidance. Female medical students generally show a trend of overrating in any of the personality dimensions.

Covariance analyses of the group differences lent support to the assumption that a response bias of over- or underrating the personality significantly influences the personality scores except of reward dependence (Table 3 ).

\section{Discussion}

The aim of the investigation was to establish baseline data of a longitudinal study on personality development of future leaders of various professions. Furthermore, differences on personality between students of economics, medicine and verbal communication sciences should be explored by means of the Temperament and Character Inventory (TCI).

The interpretation of these preliminary results from the $1^{\text {st }}$ wave of this survey is limited by its relatively small sample size. However, on the long run data from this prospective investigation should enable us to draw conclusions about possible important personality traits of the various professions which be more markedly developed during university training and during the first years of the occupational practice.

Several differences, especially between students of economics and the both other groups, i.e. students of medicine and of verbal communication, were found (research question A). Economics students described themselves as more reserved, controlled and restrained, frugal or stingy (NS3) as well as more uninhibited, nonchalant, carefree (HA1), bold, forward, outgoing and seldom inhibited by uncertainty of unfamiliarity (HA3) and rather practical, tough minded, odd, aloof with difficulties to establish social rapport (RD1), generally more practical, cold, withdrawn, detached, and independent (RD) compared with medical students and students of communication. The latter group reported an even lower degree of these characteristics than the medical students. Furthermore, students of economics rated themselves as more resourceful, effective, productive, competent, and innovative, and tended to look at difficult situations rather as challenges or opportunities (SD3), with a higher self-discipline, more rarely confusing their priorities and feeling, more often safe and self-trusting (SD5), as well as they describe themselves generally as more mature, strong, responsible, goaloriented, reliable, and constructive (SD) compared with medical students and students of communication. On the other hand, economics students described themselves as more opportunistic with a tendency to treat people unfairly in a self-serving manner, behaving more often manipulative and deceitful (CO5) as compared with the other two groups. These differences correspond mainly to those based on other measurements like the NEO-PI and the Myers-Briggs temperament types and, therefore, have to be regarded as a construct validation of these results and as construct volition of the TCI (question B). 
Table 1.

Comparisons of means of the personality scores among student groups.

\begin{tabular}{|c|c|c|c|c|c|c|c|c|c|c|c|c|c|}
\hline & \multirow{2}{*}{$\begin{array}{l}\frac{\text { Medicals }}{\underline{\text { students }}} \\
\mathrm{N}=65\end{array}$} & \multirow{2}{*}{$\begin{array}{c}\frac{\text { Economics }}{\text { students }} \\
\mathrm{N}=84\end{array}$} & \multirow{2}{*}{$\begin{array}{c}\frac{\text { Communication }}{\text { students }} \\
\mathrm{N}=43\end{array}$} & \multicolumn{2}{|c|}{ 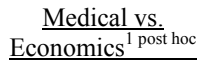 } & \multicolumn{2}{|c|}{ 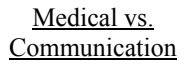 } & \multicolumn{2}{|c|}{ 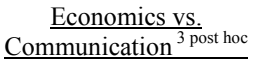 } & \multicolumn{2}{|c|}{$\underline{1 \text { way }}$} & \multicolumn{2}{|c|}{$\underline{\underline{\text { Significant }}} \underline{\text { Post hoc tests } / \mathrm{P}}$} \\
\hline & & & & $\mathrm{t}$ & $\mathrm{p}$ & $\mathrm{t}$ & $\mathrm{p}$ & $\mathrm{t}$ & $\mathrm{p}$ & F & Sig. & 1 & 3 \\
\hline Age & $22.3 \pm 2.4$ & $22.4 \pm 2.3$ & $22.7 \pm 2.8$ & -0.34 & 0.733 & -0.82 & 0.416 & -0.61 & 0.540 & 0.38 & 0.687 & & \\
\hline NS1 & $7.1 \pm 2.5$ & $7.2 \pm 2.1$ & $7.3 \pm 2.0$ & -0.30 & 0.764 & -0.65 & 0.517 & -0.46 & 0.646 & 0.23 & 0.798 & & \\
\hline NS2 & $4.1 \pm 2.5$ & $4.0 \pm 2.2$ & $4.3 \pm 2.0$ & 0.27 & 0.791 & -0.46 & 0.647 & -0.78 & 0.436 & 0.27 & 0.764 & & \\
\hline NS3 & $5.6 \pm 2.0$ & $4.9 \pm 1.8$ & $6.0 \pm 2.0$ & 2.17 & 0.032 & -0.90 & 0.370 & -2.90 & 0.004 & 4.69 & 0.010 & & 0.014 \\
\hline NS4 & $4.3 \pm 1.7$ & $4.2 \pm 1.9$ & $4.6 \pm 1.6$ & .44 & 0.661 & -0.91 & 0.367 & -1.27 & 0.206 & 0.85 & 0.431 & & \\
\hline NS & $21.1 \pm 6.1$ & $20.3 \pm 5.0$ & $22.3 \pm 4.4$ & .87 & 0.387 & -1.07 & 0.284 & -2.16 & 0.033 & 1.95 & 0.145 & & \\
\hline HA1 & $4.5 \pm 2.6$ & $3.7 \pm 1.8$ & $5.0 \pm 2.7$ & 2.29 & 0.024 & -0.84 & 0.414 & -3.22 & 0.002 & 5.21 & 0.006 & 0.074 & 0.009 \\
\hline HA2 & $3.9 \pm 2.0$ & $3.7 \pm 1.9$ & $4.5 \pm 1.6$ & 0.57 & 0.570 & -1.65 & 0.101 & -2.36 & 0.020 & 2.58 & 0.079 & & 0.077 \\
\hline HA3 & $4.0 \pm 2.1$ & $3.0 \pm 1.9$ & $3.8 \pm 1.9$ & 2.99 & 0.003 & 0.44 & 0.661 & -2.27 & 0.025 & 5.26 & 0.006 & 0.008 & 0.084 \\
\hline HA4 & $2.8 \pm 1.8$ & $2.2 \pm 1.8$ & $3.0 \pm 2.2$ & 1.97 & 0.051 & -0.64 & 0.525 & -2.29 & 0.024 & 3.31 & 0.039 & & 0.060 \\
\hline HA & $15.2 \pm 6.2$ & $12.6 \pm 5.4$ & $16.3 \pm 6.1$ & 2.75 & 0.007 & -0.92 & 0.359 & -3.53 & 0.001 & 6.96 & 0.001 & 0.022 & 0.002 \\
\hline RD1 & $6.4 \pm 2.1$ & $5.5 \pm 1.9$ & $6.5 \pm 1.8$ & 2.90 & 0.004 & -0.35 & 0.727 & -3.09 & 0.002 & 6.38 & 0.002 & 0.010 & 0.010 \\
\hline RD3 & $5.9 \pm 2.0$ & $5.9 \pm 2.0$ & $6.6 \pm 1.5$ & -0.03 & 0.979 & -1.78 & 0.079 & -1.82 & 0.071 & 1.85 & 0.159 & & \\
\hline RD4 & $4.1 \pm 1.3$ & $3.8 \pm 1.4$ & $4.2 \pm 1.3$ & 1.55 & 0.124 & -0.30 & 0.763 & -1.67 & 0.098 & 1.90 & 0.153 & & \\
\hline $\mathrm{RD}$ & $16.4 \pm 3.9$ & $15.1 \pm 3.9$ & $17.3 \pm 3.3$ & 2.01 & .046 & -1.21 & 0.229 & -3.10 & 0.002 & 5.15 & 0.007 & & 0.008 \\
\hline PS & $4.6 \pm 2.1$ & 4. $7 \pm 2.0$ & $3.9 \pm 1.9$ & -0.30 & 0.762 & 1.78 & 0.079 & 2.25 & 0.026 & 2.52 & 0.084 & & 0.094 \\
\hline SD1 & $6.2 \pm 1.7$ & $6.6 \pm 1.6$ & $6.1 \pm 2.2$ & -1.26 & 0.211 & 0.362 & 0.718 & 1.42 & 0.157 & 1.25 & 0.290 & & \\
\hline SD2 & $6.4 \pm 1.6$ & $6.8 \pm 1.4$ & $6.0 \pm 1.8$ & -1.60 & 0.112 & 1.14 & 0.256 & 2.67 & 0.009 & 3.61 & 0.029 & & 0.027 \\
\hline SD3 & $3.9 \pm 1.3$ & $4.4 \pm 0.9$ & $3.7 \pm 1.4$ & -2.83 & 0.005 & 0.92 & 0.359 & 3.69 & 0.001 & 6.92 & 0.001 & 0.027 & 0.002 \\
\hline SD4 & $7.0 \pm 2.8$ & $7.6 \pm 2.6$ & $6.9 \pm 2.6$ & -1.42 & 0.157 & 0.16 & 0.874 & 1.47 & 0.145 & 1.47 & 0.233 & & \\
\hline SD5 & $8.6 \pm 2.2$ & $9.3 \pm 1.9$ & $8.1 \pm 2.4$ & -2.02 & 0.046 & 1.19 & 0.237 & 3.08 & 0.003 & 4.95 & 0.008 & & 0.008 \\
\hline SD & $32.1 \pm 6.8$ & $34.7 \pm 5.7$ & $30.7 \pm 8.1$ & -2.46 & 0.015 & 0.95 & 0.343 & 3.15 & 0.002 & 5.55 & 0.005 & 0.069 & 0.006 \\
\hline $\mathrm{CO} 1$ & $6.8 \pm 1.2$ & $6.9 \pm 1.5$ & $6.4 \pm 1.7$ & -0.20 & 0.839 & 1.41 & 0.161 & 1.52 & 0.131 & 1.44 & 0.239 & & \\
\hline $\mathrm{CO} 2$ & $4.9 \pm 1.2$ & $4.9 \pm 1.2$ & $5.0 \pm 1.4$ & -0.33 & 0.742 & -0.55 & 0.583 & -0.29 & 0.769 & 0.16 & 0.855 & & \\
\hline $\mathrm{CO} 3$ & $6.3 \pm 1.0$ & $6.0 \pm 1.2$ & $6.0 \pm 1.0$ & 1.23 & 0.221 & 1.56 & 0.121 & 0.39 & 0.698 & 1.25 & 0.288 & & \\
\hline $\mathrm{CO} 4$ & $7.4 \pm 2.4$ & $6.5 \pm 2.8$ & $6.6 \pm 2.9$ & 2.26 & 0.025 & 1.66 & 0.100 & -0.26 & 0.793 & 2.64 & 0.074 & 0.085 & \\
\hline $\mathrm{CO} 5$ & $7.2 \pm 1.1$ & $6.7 \pm 1.6$ & $7.0 \pm 1.2$ & 2.44 & 0.016 & 0.87 & 0.389 & -1.33 & 0.188 & 3.26 & 0.041 & 0.040 & \\
\hline $\mathrm{C}$ & $32.7 \pm 4.6$ & $31.0 \pm 5.7$ & $30.9 \pm 5.7$ & 1.92 & 0.057 & 1.63 & 0.106 & -0.04 & 0.965 & 204 & 0.133 & & \\
\hline ST1 & $4.4 \pm 2.8$ & $4.1 \pm 2.5$ & $4.4 \pm 2.4$ & 0.62 & 0.533 & -0.08 & 0.936 & -0.68 & 0.501 & 0.30 & 0.742 & & \\
\hline ST2 & $2.3 \pm 1.6$ & $1.8 \pm 1.5$ & $2.3 \pm 1.8$ & 1.98 & 0.050 & -0.15 & 0.882 & -1.86 & 0.066 & 2.57 & 0.079 & & \\
\hline ST3 & $4.7 \pm 3.5$ & 4. $4 \pm 3.2$ & $5.5 \pm 3.5$ & 0.44 & 0.657 & -1.24 & 0.219 & -1.76 & 0.081 & 1.53 & 0.220 & & \\
\hline ST & $11.3 \pm 6.3$ & $10.3 \pm 5.6$ & $12.2 \pm 6.3$ & 1.04 & 0.300 & -0.76 & 0.451 & -1.79 & 0.076 & 1.59 & 0.207 & & \\
\hline
\end{tabular}

NS1 exploratory excitability vs. rigidity, NS2 impulsiveness vs. reflection, NS3 extravagance vs. reserve, NS4 disorderliness vs. Regimentation, HA1 anticipatory worry vs. optimism, HA2 fear of uncertainty vs. confidence, HA3 shyness vs. gregariousness, HA4 Fatigability and Asthenia vs. Vigor, RD1 sentimentality vs. insensitiveness, RD3 attachment vs. detachment, RD4 dependence vs. Independence, SD1 responsibility vs. blaming, SD2 purposefulness vs. lack of goal direction, SD3 resourcefulness vs. inertia, SD4 self-acceptance vs. self-striving, SD5 impulse control vs. bad habits, CO1 social acceptance vs. social intolerance, CO2 empathy vs. social disinterest, ST3 spiritual acceptance vs. rational materialism CO3 helpfulness vs. unhelpfulness, CO4 compassion vs. revengefulness, CO5 pure hearted principles vs. self-serving advantage, ST1 creative self-forgetfulness vs. self-conscious experience, ST2 transpersonal identification vs. personal identification. 
Table 2.

Performance score comparison between student group.

\begin{tabular}{|c|c|c|c|c|c|c|c|c|c|c|c|c|}
\hline & \multicolumn{4}{|c|}{ Medical } & \multicolumn{4}{|c|}{ Economics } & \multicolumn{4}{|c|}{ Communication } \\
\hline & Score & Performance & $\mathrm{t}$ & $\mathrm{p}$ & Score & Performance & $\mathrm{t}$ & $\mathrm{p}$ & Score & Performance & $\mathrm{t}$ & $\mathrm{p}$ \\
\hline NS & $21.4 \pm 6.1$ & $20.5 \pm 2.9$ & 1.11 & 0.270 & $20.3 \pm 5.0$ & $20.4 \pm 2.3$ & -0.14 & 0.888 & $22.3 \pm 4.4$ & $21.0 \pm 2.7$ & 2.06 & 0.045 \\
\hline HA & $15.2 \pm 6.2$ & $16.2 \pm 3.0$ & -1.52 & 0.134 & $12.6 \pm 5.4$ & $16.6 \pm 2.8$ & -7.05 & 0.001 & $16.3 \pm 6.1$ & $16.1 \pm 2.5$ & 0.24 & 0.813 \\
\hline $\mathrm{RD}$ & $16.4 \pm 3.9$ & $15.2 \pm 1.6$ & 2.41 & 0.019 & $15.1 \pm 3.9$ & $15.3 \pm 1.6$ & -0.40 & 0.688 & $17.3 \pm 3.3$ & $14.9 \pm 1.6$ & 4.66 & 0.001 \\
\hline PS & $4.6 \pm 2.1$ & $3.7 \pm 0.8$ & 3.75 & 0.001 & $4.7 \pm 2.0$ & $3.7 \pm 0.7$ & 4.95 & 0.001 & $3.9 \pm 1.9$ & $3.5 \pm 0.8$ & 1.48 & 0.145 \\
\hline SD & $32.1 \pm 6.8$ & $27.3 \pm 7.5$ & 5.37 & 0.001 & $34.7 \pm 5.7$ & $28.5 \pm 5.8$ & 9.08 & 0.001 & $30.7 \pm 8.1$ & $26.6 \pm 9.0$ & 4.03 & 0.001 \\
\hline $\mathrm{CO}$ & $32.7 \pm 4.6$ & $30.0 \pm 3.8$ & 5.34 & 0.001 & $31.0 \pm 5.7$ & $30.5 \pm 3.5$ & 0.95 & 0.343 & $31.0 \pm 5.7$ & $29.2 \pm 4.6$ & 2.49 & 0.017 \\
\hline ST & $11.3 \pm 6.3$ & $11.4 \pm 2.8$ & -0.19 & 0.852 & $10.3 \pm 5.6$ & $10.4 \pm 2.8$ & -0.25 & 0.807 & $12.2 \pm 6.3$ & $10.9 \pm 3.5$ & 1.89 & 0.065 \\
\hline
\end{tabular}

Table 3.

Relative frequencies of over- and underrating according to students' speciality (in \%) and covariance analyses with related performance scores as covariate variable and students' speciality as fixed factor.

\begin{tabular}{|c|c|c|c|c|c|c|c|c|c|}
\hline & \multicolumn{2}{|c|}{$\underline{\text { Medical }}$} & \multicolumn{2}{|c|}{ Economical } & \multicolumn{2}{|c|}{$\underline{\text { Communication }}$} & \multicolumn{3}{|c|}{$\underline{\text { Covariance analyses }}$} \\
\hline & $\underline{\text { over }}$ & $\underline{\text { under }}$ & over & $\underline{\text { under }}$ & over & $\underline{\text { under }}$ & $\underline{F}$ & $\underline{P}$ & $\underline{\eta^{2}}$. \\
\hline NS & 1.5 & 3.1 & 0.0 & 1.2 & 7.0 & 0.0 & 49.19 & $<0.001$ & 0.208 \\
\hline HA & 3.1 & 6.2 & 1.2 & 19.0 & 7.0 & 0.0 & 29.89 & $<0.001$ & 0.138 \\
\hline $\mathrm{RD}$ & 4.6 & 4.6 & 3.6 & 3.6 & 9.3 & 0.0 & 2.67 & 0.104 & 0.014 \\
\hline PS & 16.9 & 1.5 & 13.1 & 1.2 & 2.3 & 2.3 & 26.42 & $<0.001$ & 0.124 \\
\hline SD & 32.3 & 1.5 & 36.9 & 1.2 & 32.6 & 4.7 & 82.05 & $<0.001$ & 0.305 \\
\hline $\mathrm{CO}$ & 10.8 & 0.0 & 3.6 & 1.2 & 7.0 & 0.0 & 85.12 & $<0.001$ & 0.313 \\
\hline ST & 12.3 & 7.7 & 6.0 & 1.2 & 11.6 & 2.3 & 103.75 & $<0.001$ & 0.357 \\
\hline
\end{tabular}

However, the students of all groups seem to overrate their ability to maintain behavior, their self-directedness, i.e. maturity, self-esteem, their effectiveness, and their cooperative abilities including their identification and acceptance of others, their tolerance, empathy, compassion, and fairness according to the significant differences between self-scorings and the guessed performance scores. The fact that the economics students obviously underrate their harm avoidance (HA) corresponds to their most pronounced overrating of their self-directed behavior, and similarly corresponds to the medical students' and students' of verbal_communication overrating of their reward dependence as well as of their cooperative abilities. In both cases, the obvious disturbed self-evaluation corresponds to their professional orientation. Physicians and persons, who like to train verbal communication abilities of others, are mainly focused on social relationships, whereas future economical leaders or managers are required to be highly self-directed and courageous, composed, and optimistic even in situations which would worry other people, in order to be able to make the right decisions for the best of their company.

These results let us conclude that the students of the various fields can be characterized by specific and varying types and impact of social desirability depending on their professional career (question C).

Nevertheless, it should be a meaningful goal during the time of the university training to reduce the distortions in students' self-evaluation, e.g., by video-controlled special training of social competencies and subsequent self-observation and self- ratings.

Consequently, future leaders and/or service providers in leading positions (physicians, communication scientists) would be enabled to use more efficiently their genuine personal potential and competencies. Our findings support the results of former investigations in medical and economics student populations. In addition, based on the psychosocial model of personality of Cloninger and co-workers (1994), some meaningful differences on personality characteristics could be detected which so far have not been reported on. The application of the performance scores which are exclusively available for the Temperament and Character Inventory (TCI) enabled us to describe these differences in more detail.

\section{References}

Barrick, M. R., Mount, M. K., \& Gupta, R. (2003). Meta-analysis of the relationship between the five-factor model of personality and Holland's occupational types. Personnel Psychology, 56, 45-74. doi:10.1111/j.1744-6570.2003.tb00143.x

Borg, M. O., \& Stranahan, H. (2002a). The effect of gender and race on student performance in principles of economics: The importance of personality type. Applied Economics, 34, 586-598.

doi: $10.1080 / 00036840110039249$

Borg, M. O., \& Stranahan, H. (2002b). Personality type and student performance in upper-level economics courses: The importance of race and gender. Journal of Economic Education, 33, 3-14. doi:10.1080/00220480209596120

Buddeberg-Fischer, B., Klaghofer, R., Abel, T., \& Buddeberg, C. 
(2003). The influence of gender and personality traits on the career planning of Swiss medical students. Swiss Medicine Weekly, 133, 535-540.

Cloninger, C. R., Przybeck, T. R., Svrakic, D. M., \& Wetzel, R. D. (1994). The Temperament and Character Inventory (TCI): A guide to its development and use. St. Louis, MO: Center for Psychobiology of Personality.

Costa, P. T., \& McCrae, R. R. (1992). Revised NEO personality inventory (NEO-PI-R) and NEO five-factor inventory (NEO-FFI) professional manual. Odessa: Psychological Assessment resources, Inc.

Hojat, M. \& Zuckerman, M. (2008). Personality and specialty interest in medical students. Medical Teacher, 30, 400-406. doi: $10.1080 / 01421590802043835$

Holland, J. L. (1985). Making vocational choices: A theory of vocational personalities and work environments. Englewood Cliffs, NJ: Prentice-Hall.

Holland, J. L. (1994). Self-directed search. Odessa, FL: Psychological Assessment Resources.
Larson, L. M., Rottinghaus, P. J., \& Borgen, F. H. (2002). Meta-analysis of big-six interests and big-five personality factors. Journal of Vocational Behavior, 61, 217-239. doi:10.1006/jvbe.2001.1854

Lievens, F., Coetsier, P., de Fruyr, F., \& de Maeseneer, J. (2002). Medical students' personality characteristics and academic performance: A five/factor model perspective. Medical Education, 36, 1050-1056. doi:10.1046/j.1365-2923.2002.01328.x

Linn, B. S., \& Zeppa, R. (1984). Does surgery attract students who are more resistant to stress?. Annals of Surgery, 200, 638-643. doi:10.1097/00000658-198411000-00014

Myers, I. (1975). Manual: Myers-Briggs type indicator. Palo Alto, California: Consulting Psychologists Press.

Ziegert, A. L. (2000). The role of personality temperament and student learning in principles of economics: further evidence. Journal of Economic Education, 31, 307-322.

Zeldow, P. B., \& Daugherty, S. R. (1991). Personality profiles and specialty choices of students from two medical schools. Academic Medicine, 66, 283-287. doi:10.1097/00001888-199105000-00012 